\title{
Development of Visual Analytical Methods for Trace Determination
}

\author{
Emiko KAnEKo \\ Department of Materials Science, Faculty of Engineering, Tohoku University, \\ Aramaki, Aoba, Sendai 980-8579, Japan
}

\begin{abstract}
In this paper our recent progress in the field of simple analytical methods is reviewed, with particular focus on the development of rapid, inexpensive, yet sensitive techniques to visualize trace elements of medical, industrial, and environmental importance. Our objective is to solve long-standing practical problems in these fields. We have repeatedly shown that visual perception is remarkably sensitive when used with our new techniques. The applicability of the proposed methods to real samples is also discussed. Making measurements visually is a method free from machinery malfunctions and serves as a simple and sensitive analytical technique, avoiding all of the practical disadvantages associated with sophisticated instrumentation as well as tedious procedures.
\end{abstract}

(Received September 8, 2003; Accepted October 28, 2003)

\begin{tabular}{|c|c|c|c|c|c|}
\hline 1 & Introduction & 247 & & Aquifer Strainers & 251 \\
\hline 2 & Ion-pair Adsorption Film Colorimetry & 247 & 6 & In-vessel Extraction of Trace Lead Using & \\
\hline \multirow[t]{3}{*}{3} & Visual Fluorimetry of Aluminium by Specific & & & Polypropylene Tube & 251 \\
\hline & Immobilization on an Octadecylsilanized Silica & & 7 & Visual Colorimetry of Urinary Protein Using & \\
\hline & Thin Layer & 249 & & Membrane Filter & 253 \\
\hline \multirow{3}{*}{\multicolumn{2}{|c|}{$\begin{array}{l}4 \text { Ring-like Concentration Induced by Poly- } \\
\text { (vinyl alcohol) } \\
5 \text { Field Test of Iron in Bore Rock for Setting }\end{array}$}} & & 8 & Conclusion & 253 \\
\hline & & 250 & 9 & Acknowledgements & 254 \\
\hline & & & 10 & References & 254 \\
\hline
\end{tabular}

\section{Introduction}

The development of rapid, simple, and inexpensive analytical methods is one of the areas of growing interest, and is starting to become more accepted again now, especially since quick decisions are needed in environmental, medical, and industrial fields. Fluorimetry and colorimetry are two of the most frequently used simple methods. However, their direct application to practical samples often suffers from a lack of sensitivity and selectivity in spite of the continual improvement of chromogenic reagents. Although solvent extraction has long been used, it has many disadvantages from a practical viewpoint. This has led to a large body of literature on alternative approaches. Over the past twenty years or so, a significant amount of effort has been expended toward the development of various solid-phase extraction systems coupled with spectrophotometry, fluorimetry, and other instrumental detection methods.

Our objective is to develop visual analytical methods for the determination of trace elements, requiring neither special apparatus nor laboratory skill. In deciding what research to undertake, we first look for a problem area in analytical chemistry with great demand for a practical solution that has yet to be solved. We then go about finding a practical way to meet this demand. The fundamental and also most important questions that we address concern (i) whether we can develop a new technique of interest in the field of analytical chemistry, (ii) the potential for practical use, and (iii) whether the method is cost-effective in terms of the real demand. In this paper, our recent progress in the field of visual tests is outlined from these viewpoints.

\section{Ion-pair Adsorption Film Colorimetry}

The first effective colorimetry that we developed was for trace aluminium ion, based on the ion-pair adsorption of its anionic chelate with 2,2'-dihydroxyazobenzene (DHAB or $\mathrm{H}_{2} \mathrm{~L}$ ) with Crystal Violet cation $\left(\mathrm{CV}^{+}\right)$on poly(vinyl chloride) (PVC) film plasticized with di- $n$-octylphthalate (DOP). ${ }^{1}$

Tanaka et al. previously described a colorimetry with Crystal Violet for the visual determination of anionic surfactant at $\mathrm{mg}$ $1^{-1}$ levels using polyvinylchloride sheets. ${ }^{2}$

In this study, when a sheet of PVC film was added to a sample solution and shaken for $30 \mathrm{~min}$ in a thermostated shaker at $70^{\circ} \mathrm{C}$, the ion-pair, $\mathrm{CV}^{+}\left[\mathrm{AlL}_{2}\right]^{-}$, was enriched onto the transparent film, leading to a remarkable enhancement in the sensitivity. The color system, consisting of red $\left(\left[\mathrm{AlL}_{2}\right]^{-}\right)$, yellow $\left(\mathrm{H}_{2} \mathrm{~L}\right)$, and blue violet $\left(\mathrm{CV}^{+}\right)$, gives distinct color changes (Fig. 1). The mechanism of coloration is shown in Fig. 2. At $[\mathrm{Al}]_{\mathrm{T}}=0$, the species adsorbed are $\mathrm{H}_{2} \mathrm{~L}$ and a small amount of reagent blank caused by aluminium contamination, and the film is khaki in color. At $\left[\mathrm{H}_{2} \mathrm{~L}\right]_{\mathrm{T}}>2[\mathrm{Al}]_{\mathrm{T}}$, the ion-pair, 


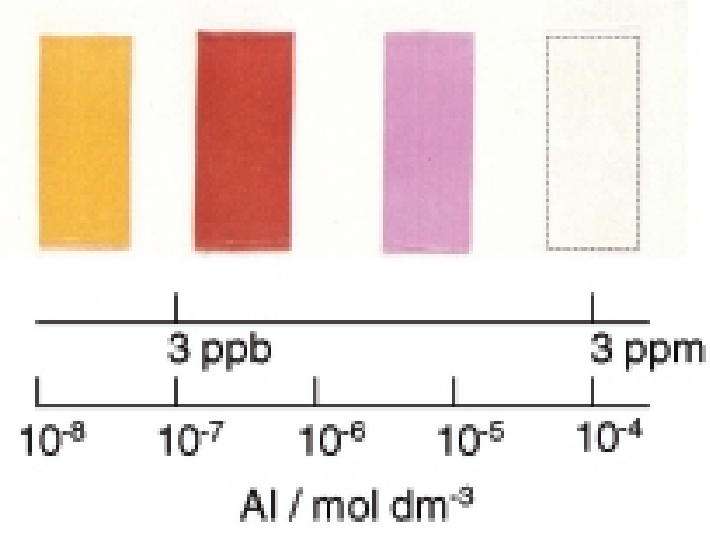

Fig. 1 Coloration for aluminium. ${ }^{1}[\mathrm{DHAB}]_{\mathrm{T}}, 2 \times 10^{-5} \mathrm{~mol} \mathrm{dm}^{-3}$; $[\mathrm{CVCl}]_{\mathrm{T}}, 2 \times 10^{-5} \mathrm{~mol} \mathrm{dm}{ }^{-3} ; \mathrm{pH}, 8.0$; temperature, $70^{\circ} \mathrm{C}$; shaking time, $30 \mathrm{~min}$.

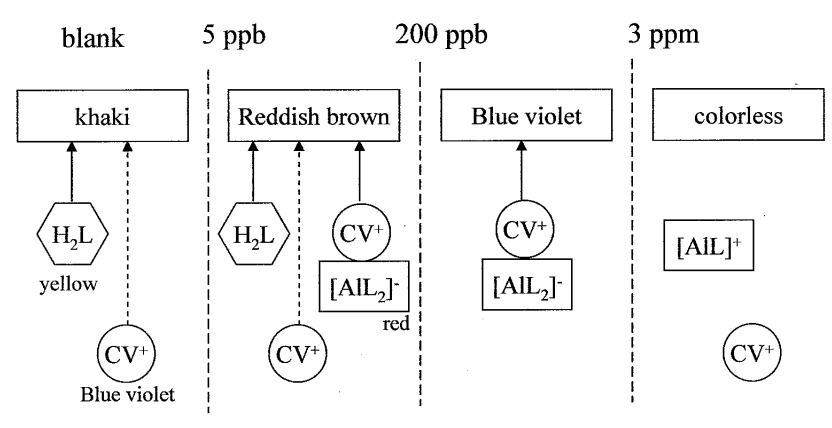

Fig. 2 Mechanism of coloration. $[\mathrm{DHAB}]_{\mathrm{T}}, 2 \times 10^{-5} \mathrm{~mol} \mathrm{dm}^{-3}$. The other conditions are the same as those in Fig. 1.

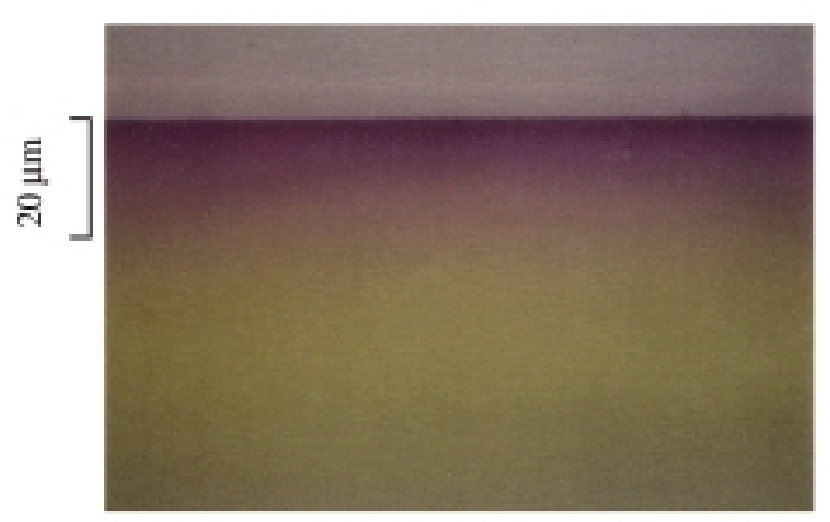

Fig. 3 Cross-section of colored film. ${ }^{1}[\mathrm{Al}]_{\mathrm{T}}, 1 \times 10^{-6} \mathrm{~mol} \mathrm{dm}^{-3}(27$ $\mathrm{ng} / \mathrm{ml}$ ). The other conditions are the same as those in Fig. 1.

$\mathrm{CV}^{+}\left[\mathrm{AlL}_{2}\right]^{-}$, is adsorbed in addition to the species described above. The resulting color is reddish-brown. In this region a linear calibration curve was obtained using a spectrophotometric measurement at $592 \mathrm{~nm}$. The detection limit, defined as the concentration equivalent to two times of the standard deviation of the blank signal, is $1 \times 10^{-7} \mathrm{~mol} \mathrm{dm}^{-3}(3$ $\mathrm{ppb}$ ). By visual observation, concentrations as low as $2 \times 10^{-7}$ mol dm ${ }^{-3}(5 \mathrm{ppb})$ can be detected. At $[\mathrm{Al}]_{\mathrm{T}}<\left[\mathrm{H}_{2} \mathrm{~L}\right]_{\mathrm{T}}<2[\mathrm{Al}]_{\mathrm{T}}$, $\mathrm{H}_{2} \mathrm{~L}$ is quantitatively consumed by complexation, and only $\mathrm{CV}^{+}\left[\mathrm{AlL}_{2}\right]^{-}$is adsorbed. Thus, the color of the film is blue
Table 1 Analytical results of aluminium in tap waters

\begin{tabular}{llrcc}
\hline & & \multicolumn{2}{c}{ This method } & \multirow{2}{*}{ Flameless AAS } \\
\cline { 3 - 4 } No. & $\begin{array}{c}\text { Sampling } \\
\text { location }\end{array}$ & $\begin{array}{c}\text { Visual } \\
\text { Al, ppb }\end{array}$ & $\begin{array}{c}\text { Spectrophotometry } \\
\text { Al, ppb }\end{array}$ & Al, ppb \\
\hline \multirow{2}{*}{1} & T. City & 6 & 7.5 & 6.8 \\
2 & H. City & 10 & 14 & 8.1 \\
3 & M. City & 12 & 20.5 & 12.6 \\
4 & N. City & 20 & 21.5 & 20.3 \\
5 & O. City & $>200$ & $>200$ & 214 \\
\hline
\end{tabular}

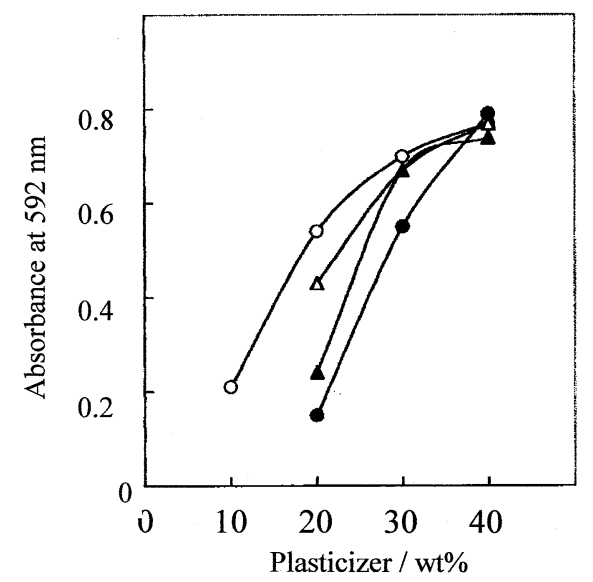

Fig. 4 Effect of plasticizers. ${ }^{3}$ Reference: reagent blank. Plasticizer: 0 , di- $n$-octylphthalate; $\Delta$, di-2-ethylhexyl phthalate; $\Delta$, di- $n$-butylphthalate; •, tricresyl phosphate. $[\mathrm{Fe}]_{\mathrm{T}}, 1.6 \times 10^{-6} \mathrm{~mol}$ $\mathrm{dm}^{-3} ;\left[\mathrm{H}_{2} \mathrm{~L}\right]_{\mathrm{T}}, 8 \times 10^{-5} \mathrm{~mol} \mathrm{dm}^{-3} ;[\mathrm{CVCl}]_{\mathrm{T}}, 2 \times 10^{-5} \mathrm{~mol} \mathrm{dm}^{-3} ; \mathrm{pH}, 4.0$ shaking time, $40 \mathrm{~min}$; temperature, $70^{\circ} \mathrm{C}$.

violet. At $[\mathrm{Al}]_{\mathrm{T}}>\left[\mathrm{H}_{2} \mathrm{~L}\right]_{\mathrm{T}}$, a non-adsorbed cationic aluminium species, $[\mathrm{AlL}]^{+}$, is formed and the film is colorless. The boundaries of the four color regions can be controlled by changing the total concentration of DHAB.

Observations of the film sections provided valuable information about the interaction between the PVC film and the extracted species (Fig. 3). The extraction of the blue violet species, $\mathrm{CV}^{+}\left[\mathrm{AlL}_{2}\right]^{-}$, is restricted to the surface region of the film, whereas the yellow reagent, $\mathrm{H}_{2} \mathrm{~L}$, is extracted into the film, showing a yellow-color homogeneously inside the film.

This method was successfully applied to the determination of aluminium in tap water (Table 1). The major interference is the iron(III) ion, but none of the other common metal ions in tap water has any significant effect. When there is a significant amount of iron(III) ion, it is masked with 1,10-phenanthroline prior to the analysis.

This method was extended to the determination of iron. ${ }^{3}$ The effect of the film composition on the response to iron was studied using DOP, tricresyl phosphate, di- $n$-butyl phthalate, and di-2-ethylhexyl phthalate as plasticizers (Fig. 4). Although the adsorption of the ion-pair increases with an increase in the plasticizer, which works as a solid-phase adsorbent, the softer film is difficult to handle. Thus, $30 \mathrm{wt} \%$ DOP-PVC was determined to be the most effective film composition.

Although film extraction is not suitable for practical use in field tests, since it takes $30 \mathrm{~min}$ and uses a thermostated shaker, this work was the first to demonstrate that a sensitive visual colorimetry at ppb levels is possible. 


\section{Visual Fluorimetry of Aluminium by Specific Immobilization on an Octadecylsilanized Silica Thin Layer}

Thin-layer chromatography is easier to run than other separation techniques, requiring no electrical energy, complex apparatus or skilled laboratory support.

In our study, a highly selective and sensitive visual fluorimetry for the determination of trace aluminium could be developed based on chromatographic separation. It was found that a positively charged fluorescent 1:1 aluminium(III) chelate $\left([\mathrm{AlL}]^{+}\right)$was retained at a spotting position when developed with an organic solvent using octadecylsilanized (ODS) silica thin layers (Fig. 5) ${ }^{4-6}$ Conversely, excess reagent and both neutral and negatively charged metal chelates were eluted close to the solvent front. Acetone was chosen over the other solvents tested because of its higher resolution.

A drop-based concentration was adopted for enriching the fluorescent aluminium chelate into a small fleck prior to chromatographic separation. When $10 \mu \mathrm{L}$ of ethanol-aqueous $(1+4)$ sample solution is applied to the hydrophobic surface of an ODS silica plate, the sample retains a spherical shape rather than spreading, as it does in conventional thin-layer chromatography (TLC). Drying the sample in an oven at $60^{\circ} \mathrm{C}$ for 10 min results in an effective enrichment of the analyte into a fleck of $3 \mathrm{~mm}$ in diameter. It should be noted that the predominant non-fluorescent chelate, $\left[\mathrm{AlL}_{2}\right]^{-}$, in the $\mathrm{pH} 7-8$

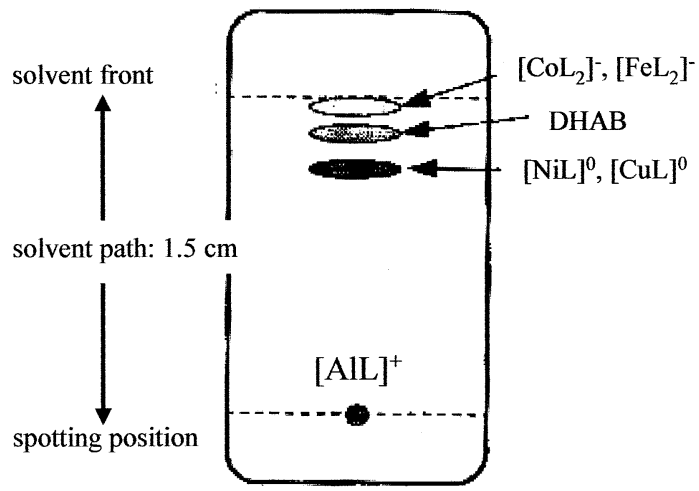

Fig. 5 Specific immobilization of aluminium. ${ }^{4}$ Developing solvent, acetone; plate, RP-18 HPTLC Art. 5914; volume of sample loading, $0.01 \mathrm{~cm}^{3}$; drying, $60^{\circ} \mathrm{C}$

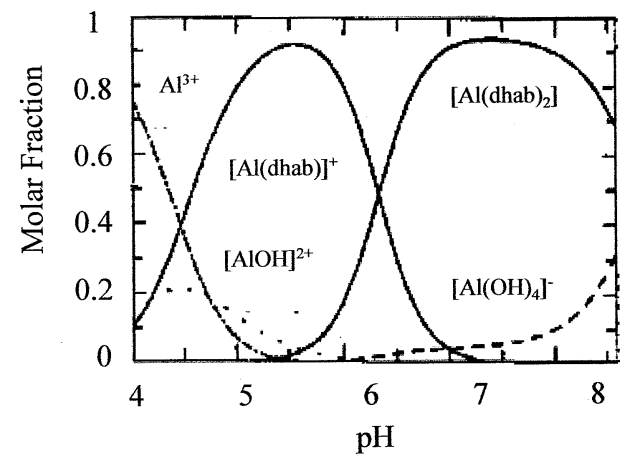

Fig. 6 Molar fraction of Al-DHAB. Samples ${ }^{5}$ : $[\mathrm{DHAB}]_{\mathrm{T}}, 3 \times 10^{-6}$ $\mathrm{mol} \mathrm{dm}{ }^{-3} ; \mathrm{Al}, 5 \times 10^{-7} \mathrm{~mol} \mathrm{dm}^{-3}$. The stability constants used for the calculation are $\log K_{1}, 16.4 ; \log K_{2}, 12.7$ for Al-DHAB; $\log K_{1}{ }^{\mathrm{OH}}$, 9.27; $\log \beta_{4}{ }^{\mathrm{OH}}, 33.03$. sample solution (Fig. 6) is converted to $[\mathrm{AlL}]^{+}$on the plate during the drying process. Figure 7 shows the fluorescent spectra of the aluminium chelate.

Our visual method has been successfully applied to the determination of ppb levels of aluminium ion in tap water, river water, and tea samples. When the fleck is viewed under ultraviolet light in the dark, the visual detection limit is $1 \mathrm{ppb}$, which is comparable to the limit when using a graphite furnace atomic absorption spectrometry (GF-AAS)

Charge difference plays an important role in thin-layer chromatographic separation. The specific immobilization of [AlL] ${ }^{+}$is attributed to the electrostatic interaction between it and the anionic charge of silanol groups on the ODS silica plate. The immobilizing phenomenon was also observed for other cationic species. The insolubility of the chelate in organic solvents also contributes to its immobilization. When the chelate is applied to solvent extraction, a considerable amount of scum forms at the two-phase interface. [AlL] ${ }^{+}$is more hydrophilic than other metal-DHAB chelates because the chelate with the tridentate ligand has water molecules in its coordination sphere.

In a separate experiment, the retention behavior of the cationic

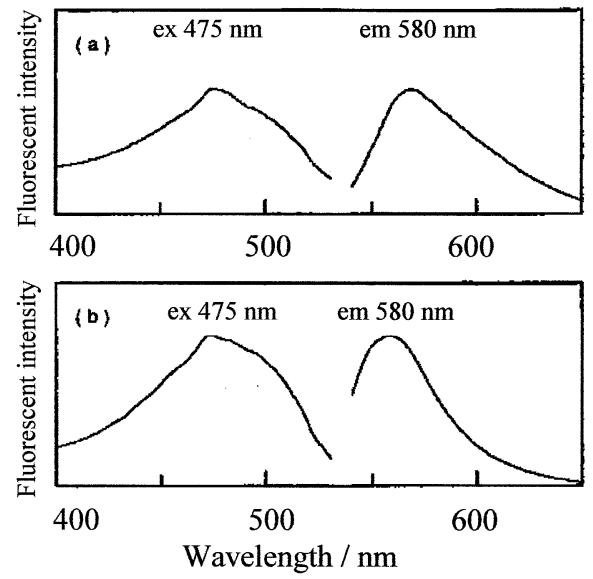

Fig. 7 Fluorescent spectra of Al-DHAB ${ }^{5}$ : (a) aqueous solution; (b) solid phase. Samples: Al, $1 \times 10^{-6} \mathrm{~mol} \mathrm{dm}^{-3}$; $[\mathrm{DHAB}]_{\mathrm{T}}, 3 \times 10^{-6} \mathrm{~mol}$ $\mathrm{dm}^{-3}$; (a) $\mathrm{pH}, 5.5$; (b) pH, 6.8 (initial solution).
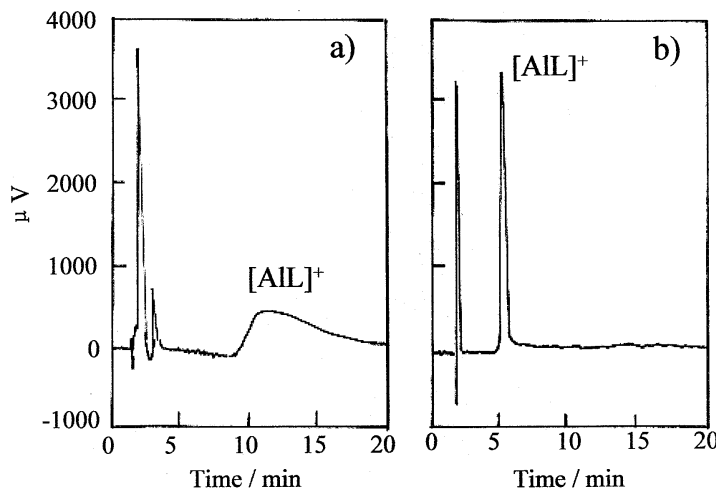

Fig. 8 Typical chromatogram of Al-DHAB 1:1 chelates. ${ }^{7}$ Sample: $\left[\mathrm{Al}^{3+}\right], 1 \times 10^{-6} \mathrm{~mol} \mathrm{dm}^{-3}$; [DHAB], $4 \times 10^{-5} \mathrm{~mol} \mathrm{dm}^{-3} ; \mathrm{pH}, 5.5$ (MES$\mathrm{NaOH}$ ). Mobile phase: $55 \mathrm{wt} \%$ methanol-water; EDTA, $10^{-4} \mathrm{~mol}$ $\mathrm{kg}^{-1}$; (a) $\mathrm{pH}, 2.0$; (b) $\mathrm{pH}$, 5.5. HPLC conditions: detection wavelength, $480 \mathrm{~nm}$; flow rate, $0.8 \mathrm{~cm}^{3} \mathrm{~min}^{-1}$; column temperature, $25^{\circ} \mathrm{C}$; column, Lichrospher RP-18. 
chelate, $[\mathrm{AlL}]^{+}$in HPLC was investigated using the ODS silica stationary phase. It was found that when the $\mathrm{pH}$ of the aqueousmethanol mobile phase was 5.5, a significant tailing of the aluminium chelate was observed, whereas when the $\mathrm{pH}$ was 2 , a marked improvement of the elution was attained (Fig. 8). ${ }^{7}$ Based on these results, the underlying immobilization mechanism of the aluminium chelate on the ODS thin-layer plate can be explained by the interaction between the cationic chelate and deprotonated silanol groups on the solid surface.

Unfortunately, this work has yet to be used in applications as a commercial kit for practical use. We believe, however, that our method will be useful for environmental analyses of trace aluminium, providing a high selectivity and sensitivity comparable to GF-AAS.

\section{Ring-like Concentration Induced by Poly(vinyl alcohol)}

It was found that poly(vinyl alcohol) (PVA) forms a ring-like solid-phase $10 \mathrm{~mm}$ in diameter when a $100 \mu \mathrm{l}$ drop of its aqueous solution was evaporated on a poly(vinyl chloride) (PVC) plate. ${ }^{8,9}$ The shape of the ring is a nearly perfect circle,
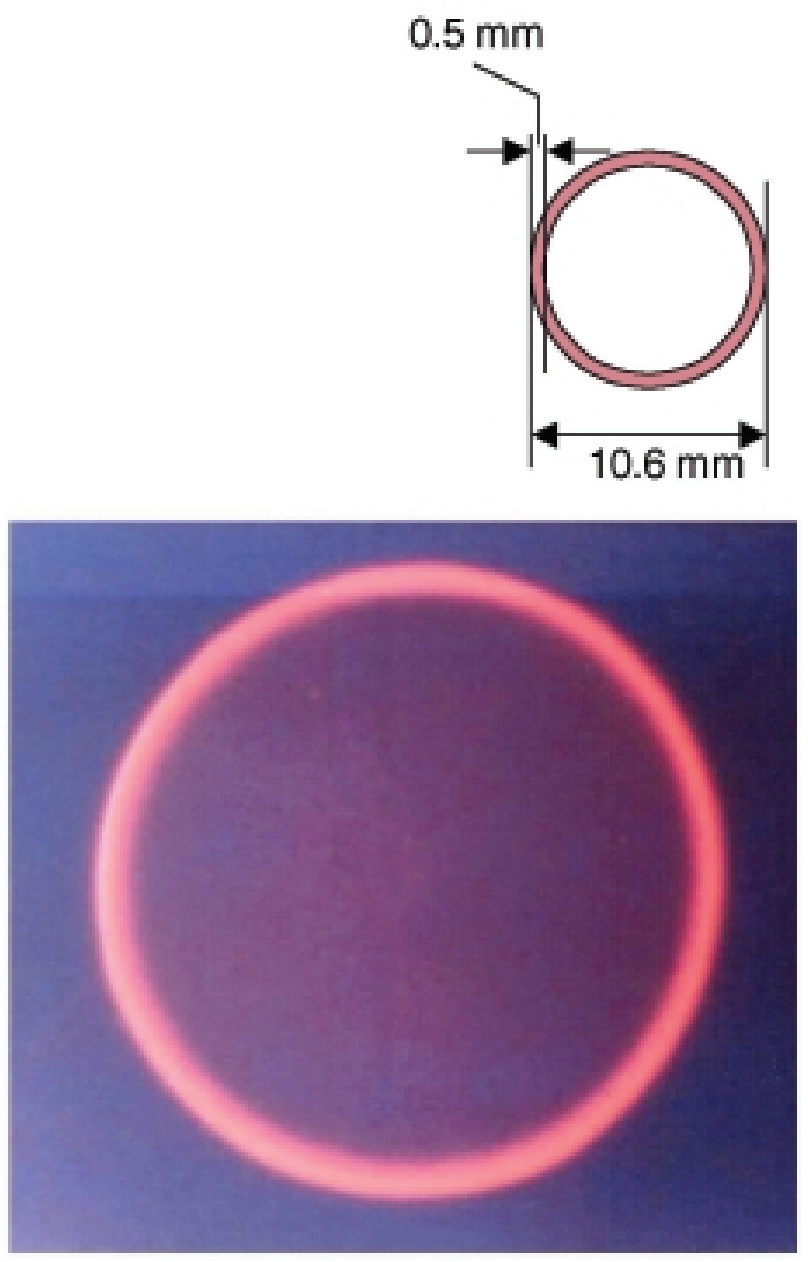

Fig. 9 Photograph of a PVA ring containing a fluorescent aluminium chelate. ${ }^{8}$ Composition of initial solution: $[\mathrm{Al}]_{\mathrm{T}}, 1 \times 10^{-6}$ mol dm${ }^{-3} ;[D H A B]_{\mathrm{T}}, 3 \times 10^{-6} \mathrm{~mol} \mathrm{dm}^{-3}$; [MES], $5 \times 10^{-3} \mathrm{~mol} \mathrm{dm}^{-3}$; $\mathrm{pH}, 5.5$; PVA, 0.25\%; volume of drop, $0.1 \mathrm{~cm}^{3}$. Substrate: PVC plate. Temperature for evaporation; $70^{\circ} \mathrm{C}$. An UV lamp was used for excitation. as shown in Fig. 9. Trace aluminium ion at ppb levels was concentrated into the ring as the fluorescent 1:1 aluminium chelate with DHAB. The ring, which exhibits florescence visible to the naked-eye under ultraviolet light in the dark, could be imaged with a densitometer (Shimadzu CS-9300PC) (Fig. 10).

The recommended procedure is as follows: $20 \mu \mathrm{l}$ of 2morpholinoethanesulfonic acid (MES) buffer solution is put on a white PVC plate, and then $30 \mu \mathrm{l}$ of DHAB aqueous solution containing $0.833 \%$ PVA and $50 \mu \mathrm{l}$ of a sample solution are added. When the aqueous drop is set on a water repellent surface of PVC, the drop retains its semi-spherical shape. The drop is evaporated to dryness at $70^{\circ} \mathrm{C}$ either on a heating plate or in an oven. The aluminium concentration is determined by a visual comparison of the fluorescent ring with a standard series under ultraviolet light in the dark.

The ring formation process was investigated using microscopy. A sample drop retains a semi-spherical shape on the PVC plate due to the water repellency of the substrate. The height of the drop decreases during evaporation, but the radius of the drop does not shrink because its contact line is pinned at the original point. Thus, PVA deposits along the perimeter, concentrating the solutes into the ring.

The diameter of the ring obtained from a $100 \mu 1$ sample drop was $10.6 \mathrm{~mm}$ with a coefficient of variation of $2.2 \%(n=8)$. The width of the ring was $0.5 \mathrm{~mm}$. The coefficient of variation of the peak height shown in Fig. 10 was $5.1 \%(n=8)$ for $1 \times$ $10^{-6} \mathrm{M}$ aluminium. The visual detection limit of aluminium is 5 $\times 10^{-8} \mathrm{M}(1.3 \mathrm{ppb})$.

It should be pointed out that the selectivity of the Ring-like concentration is relatively limited. In this study, the fluorescent 1:1 chelate provided a sufficient selectivity for aluminium in practical samples. The choice of the chromogenic reagent is a key factor to develop practical methods for trace analysis. Instrumental measurements would also be useful when coupled with Ring-like concentrations.

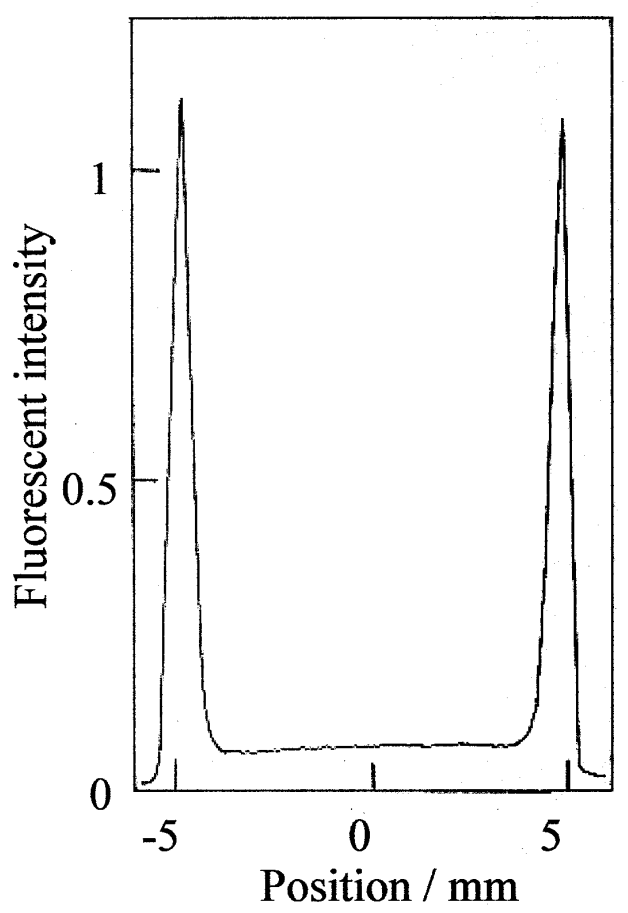

Fig. 10 Fluorometric densitogram of a ring. Beam size; $0.4 \times 0.4$ $\mathrm{mm}$. The other conditions are the same as those in Fig. 9. 

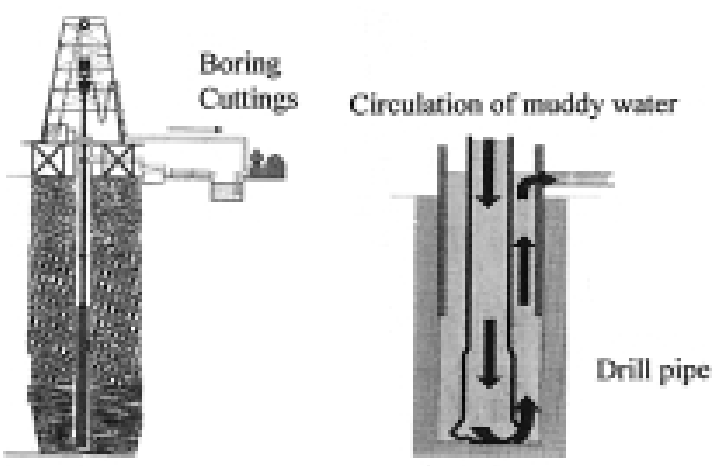

Fig. 11 Rotary method for well construction.

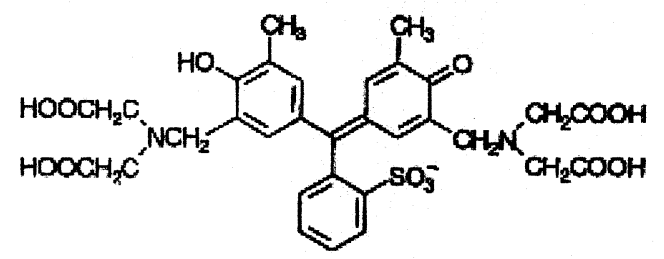

Fig. 12 Xylenol Orange (XO).

\section{Field Test of Iron in Bore Rock for Setting Aquifer Strainers}

In the field of well construction, a reliable and rapid method for the prediction of water quality in groundwater has been long desired. The quality of groundwater depends on the nature of aquifers, and since water samples from aquifers are not available during well construction, the rocks from the aquifers are the only samples that can be analyzed (Fig. 11). Furthermore, the quality of the water needs to be accurately estimated as soon as possible after the aquifers have been drilled and before the well casing is set. One of the best indicators of water quality in wells is the iron content.

In this study, a simple, rapid, and inexpensive method for the determination of iron content in rock samples was developed. This method is based on the color-development properties of the iron(III)-Xylenol Orange (XO, Fig. 12) system, which turns yellow, red, and purple blue as the iron concentration increases. The test is performed with an aqueous drop on a Teflon plate (Fig. 13). When the iron content exceeds a certain level, a distinct color change from yellow to purple blue appears in the drop, which contains a $10 \mathrm{mg}$ rock sample, hydrochloric acid, $\mathrm{XO}$, and ammonium peroxodisulfate.

The recommended procedure is as follows: add $40 \mu \mathrm{l}$ of 0.02 $\mathrm{M}\left(1 \mathrm{M}=1 \mathrm{~mol} \mathrm{dm}^{-3}\right)$ hydrochloric acid to about $10 \mathrm{mg}$ of rock sample on a poly(tetrafluoroethylene) plate $(80 \times 150 \times 2 \mathrm{~mm})$. The rock sample is engulfed in a hemispherical drop on the plate throughout this test. Let the reaction mixture stand for 5 min to leach iron ions from the rock. Add $10 \mu \mathrm{l}$ of $0.1 \mathrm{M}$ ammonium peroxodisulfate and $40 \mu \mathrm{l}$ of $250 \mu \mathrm{M}$ XO (Dojin Co. Ltd., Kumamoto, Japan) and then let the drop remain undisturbed for the colors to develop. The level of iron(III) concentration is evaluated from the color of the drop. When the color of the drop is yellow, it indicates a low iron content $(<44$ $\mu \mathrm{M}$ in the final drop) in the rock sample. The color range from deep reddish yellow to dark red indicates a significantly high iron content $(44-110 \mu \mathrm{M})$, and a purple blue drop indicates an
$4041,2.5 \times 10^{-5} \mathrm{M}$

Xylenol Orange

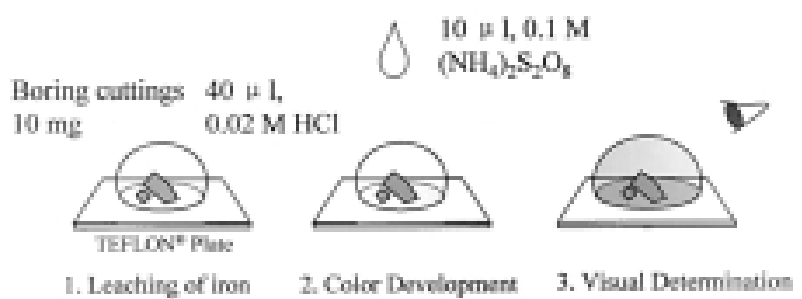

Fig. 13 Procedure for the iron test.

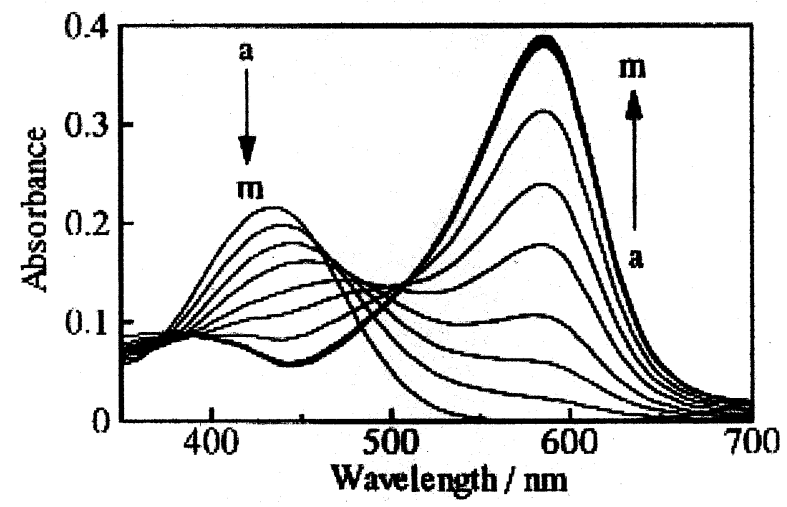

Fig. 14 Absorption spectra of $1.1 \times 10^{-4} \mathrm{~mol} \mathrm{dm}^{-3} \mathrm{XO}$ with varied amounts of total iron(III) at $\mathrm{pH} 2 .^{10}[\mathrm{Fe}(\mathrm{III})] / 10^{-6} \mathrm{~mol} \mathrm{dm}^{-3}$ : a, 0 ; b, 22; c, 44; d, 66; e, 88; f, 110; g, 130; h, 150; i, 180; j, 200; k, 220; 1, $330 ; \mathrm{m}, 440 .\left[\left(\mathrm{NH}_{4}\right)_{2} \mathrm{~S}_{2} \mathrm{O}_{8}\right]$ was $11 \times 10^{-3} \mathrm{~mol} \mathrm{dm}^{-3}$.

even higher iron content $(>110 \mu \mathrm{M})$. When the results by the proposed method showed purple blue, the iron concentrations in the well water were higher than the quality criterion of 0.3 $\mathrm{mg} / \mathrm{L}$. Figure 14 shows the absorption spectra of the iron(III)$\mathrm{XO}$ system at $\mathrm{pH} 2$ with various iron(III) concentrations.

In the relationship between the molar ratio and the absorbance at $585 \mathrm{~nm}$ and $540 \mathrm{~nm}$, both at $\mathrm{pH} \mathrm{2,} \mathrm{two} \mathrm{bending} \mathrm{points} \mathrm{were}$ obtained. Although the compositions of the iron-XO complexes could not be identified, since the commercially available XO contains impurities, such as semi-XO and iminodiacetate, the results suggested the existence of 1:1 and 2:1 (M:L) complexes. The reagent, which has two geometrically isolated coordination sites in a molecule, probably forms a $2: 1$ complex in the presence of excess iron(III) ion.

Aluminium ion forms a red-purple chelate with an absorption maximum at $555 \mathrm{~nm}$ under the same conditions. However, the reaction of the aluminium ion with $\mathrm{XO}$ is sufficiently slow, so that up to $1 \mathrm{mM}$ of aluminium ion is tolerated when the colors due to iron(III)-XO complexes are detected within $3 \mathrm{~min}$.

This method is commercially available, and has been used by drillers for years as a field test kit.

\section{In-vessel Extraction of Trace Lead Using Polypropylene Tube}

The toxicity of lead to living organisms has been recognized for many years. The measurement of lead both in environmental and in biological samples has become of prime importance in protecting the population from this long-term health hazard.

In this study, a new method was developed for the solid-phase 

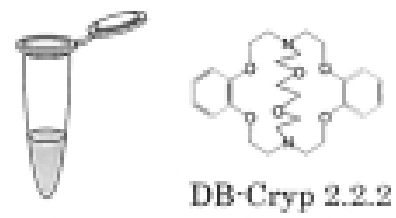

Bxtraction
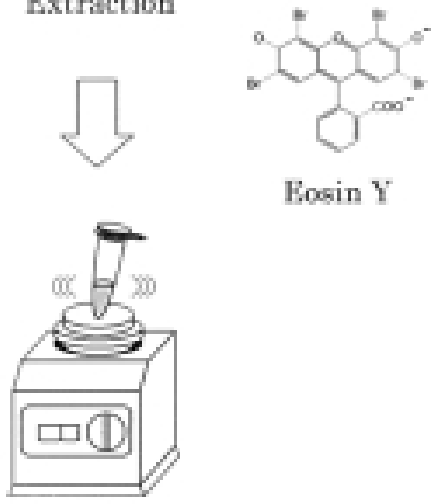

Rosin Y

Elution

Table 2 Effect of foreign ions

\begin{tabular}{lcccc}
\hline Ion & $\begin{array}{c}\text { Added amount/ } \\
\mathrm{mg} \mathrm{l^{-1 }}\end{array}$ & $\begin{array}{c}\text { Molar ratio } \\
\text { foreign ion/Pb(II) }\end{array}$ & $\begin{array}{c}\mathrm{Pb} \text { found/ }_{\mu \mathrm{g} \mathrm{l}^{-1}} \\
\%\end{array}$ & $\begin{array}{c}\text { Recovery, } \\
\%\end{array}$ \\
\hline $\mathrm{Na}^{+}$ & 229 & 100000 & $20.7^{\mathrm{a}}$ & 100 \\
$\mathrm{~K}^{+}$ & 391 & 100000 & $24.6^{\mathrm{a}}$ & 119 \\
$\mathrm{Ca}^{2+}$ & 40.0 & 1000 & $19.1^{\mathrm{a}}$ & 92.5 \\
$\mathrm{Mg}^{2+}$ & 243 & 10000 & $19.1^{\mathrm{a}}$ & 93.0 \\
$\mathrm{Zn}^{2+}$ & 3.15 & 100 & 100 & 100 \\
$\mathrm{Ni}^{2+}$ & 10.0 & 352 & 101 & 101 \\
$\mathrm{Al}^{3+}$ & 0.130 & 10 & 98.2 & 98.2 \\
$\mathrm{Mn}^{2+}$ & 10.0 & 377 & 96.0 & 96.0 \\
$\mathrm{As}^{3+}$ & 3.62 & 100 & 95.6 & 95.6 \\
$\mathrm{Cd}^{2+}$ & 0.543 & 10 & 99.4 & 99.4 \\
$\mathrm{Sn}^{2+}$ & 0.573 & 10 & 15.7 & 15.7 \\
$\mathrm{Hg}^{2+}$ & 0.969 & 10 & 102 & 102 \\
$\mathrm{Fe}^{3+}$ & 0.269 & 10 & 72.6 & 72.6 \\
$\mathrm{Fe}^{2+}$ & $10.0^{\mathrm{b}}$ & 370 & 99.2 & 99.2 \\
$\mathrm{Cu}^{2+}$ & 0.064 & 10 & $51.8^{\mathrm{a}}$ & 250 \\
$\mathrm{Cu}^{+}$ & $3.06^{\mathrm{b}}$ & 100 & 96.5 & 96.5 \\
$\mathrm{Cr}^{3+}$ & 0.251 & 10 & 115 & 115 \\
\hline $\mathrm{Pb}^{2+}$ & 100 & & & \\
\hline
\end{tabular}

Pb taken: $100 \mu \mathrm{g} \mathrm{L}^{-1}$ except for a) $\mathrm{Pb}$ taken: $20.7 \mu \mathrm{g} \mathrm{L} \mathrm{L}^{-1}$, b) with $\mathrm{L}(+)$-ascorbic acid.

Fig. 15 In-vessel extraction and elution.

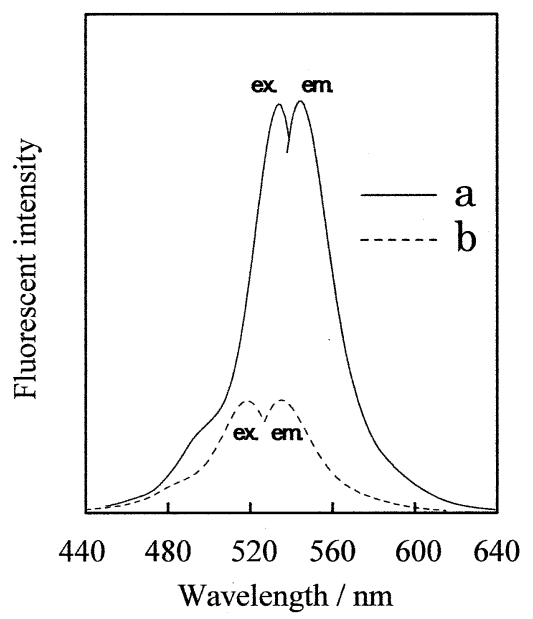

Fig. 16 Fluorescent spectra of Eosin Y. ${ }^{12}$ (a) Ethanol-water $(4+1)$; (b) aqueous solution; Eosin Y, $1.0 \times 10^{-8} \mathrm{~mol} \mathrm{l}^{-1}$; $\mathrm{pH}, 7.0$.

extraction of lead using a polypropylene tube. ${ }^{12}$ The ion-pair of the lead complex with 5,6-14,15-dibenzo-4,7,13,16,21,24hexaoxa-1,10-diazabicyclo $(8,8,8)$ hexacosane (DibenzoCryptand 2.2.2 or DB-Cryp 2.2.2, Tokyo Kasei Kogyo Co.) and Eosin Y was extracted onto a tube wall (Fig. 15). The ion-pair was easily eluted into a small volume of aqueous ethanol, and the lead concentration in the elution solution was then determined by fluorimetry. Eosin $\mathrm{Y}\left(\mathrm{Y}^{2-}\right)$ shows an excitation maximum at $534 \mathrm{~nm}$ and an emission maximum at $544 \mathrm{~nm}$ at pH 7.0 in ethanol-water $(4+1)$ (Fig. 16).

A typical procedure is as follows: a sample solution of $800 \mu \mathrm{l}$ containing less than $0.3 \mu \mathrm{g}$ lead ion was pipetted into a $1.5 \mathrm{~mL}$ microtube. The following solutions were added to the sample: $50 \mu \mathrm{l}$ of $1 \times 10^{-3} \mathrm{~mol} \mathrm{l}^{-1}$ DB-Cryp 2.2.2 solution, $100 \mu \mathrm{l}$ of 0.1 mol 1-1 2-[4-(2-hydroxyethyl)-1-piperazinyl]ethanesulfonic acid (HEPES)-LiOH buffer solution ( $\mathrm{pH} 7.0)$ and $50 \mu \mathrm{l}$ of $1 \times 10^{-4}$ mol $\mathrm{l}^{-1}$ Eosin Y solution. The mixture was diluted with doubly distilled water to $1 \mathrm{ml}$. After letting the solution stand at room

temperature for $1 \mathrm{~min}$ for extraction to take place, it was disposed of, and the tube was rinsed with $1 \mathrm{ml}$ of water. Five hundred microliters of ethanol-water $(4+1)$ was put into the tube. The analyte was then eluted from the tube wall into the back-extraction solvent using a vortex mixer for approximately 10 s. Following back-extraction, fluorimetry with a $300-\mu 1$ microcell was carried out.

When a $50 \mu \mathrm{l}$ aliquot of the back-extraction solution was set on a Teflon plate, $5 \times 10^{-8} \mathrm{~mol} \mathrm{l}^{-1}\left(10 \mu \mathrm{g} \mathrm{l}^{-1}\right)$ of lead could be visually detected in the drop under ultraviolet light in the dark. The fluorimetric calibration curve is linear over the concentration range up to $1.5 \times 10^{-6} \mathrm{~mol} \mathrm{l}^{-1}\left(310 \mu \mathrm{g} \mathrm{l}^{-1}\right)$. The detection limit, defined as the concentration equivalent to threetimes the standard deviation of the background signal, is $3 \times 10^{-8} \mathrm{~mol} \mathrm{l}^{-1}\left(6 \mu \mathrm{g} \mathrm{l}^{-1}\right)$. The between-batch coefficient of variation for ten samples of $100 \mu \mathrm{g} \mathrm{l}^{-1}$ was $8.9 \%$.

The effect of foreign metal ions on the lead signal is summarized in Table 2. The results show that sodium and potassium ions are tolerated up to 100000 -fold concentrations for $1 \times 10^{-7} \mathrm{~mol} \mathrm{l}^{-1}$ lead. The interference from copper(II) and iron(III) ions can be removed using L-ascorbic acid. In addition to the stability of the DB-Cryp 2.2.2-lead complex, the charge effect in ion-pair extraction with the divalent counter ion, Eosin $\mathrm{Y}\left(\mathrm{Y}^{2-}\right)$, shown as the following equation, contributes to its higher selectivity for lead over the other alkaline ions:

[Pb-DB-Cryp 2.2.2 $]^{2+}+$ Eosin $\mathrm{Y}^{2-}$

$$
\rightleftharpoons[\mathrm{Pb}-\mathrm{DB}-\mathrm{Cryp} \text { 2.2.2 }]^{2+} \text { Eosin } \mathrm{Y}^{2-}{ }_{\mathrm{s}}
$$

where the subscript $\mathrm{s}$ indicates the species in the solid phase. Although an ODS silica disk cartridge can also be used for the ion-pair extraction, ${ }^{13,14}$ a polypropylene tube was chosen as a primer because of its cost effectiveness.

The cost of this system, which utilizes little energy and requires no complex apparatus, is significantly lower than other instrumental methods. A field-test kit for trace lead in tap water was developed based on this work, and became commercially available in 2002 . 
<smiles>O=C1C(Cl)=CC(=C(c2cc(Cl)c(O)c(Br)c2)c2ccccc2S(=O)(=O)[O-])C=C1Br</smiles>

$\mathrm{BCPB}$

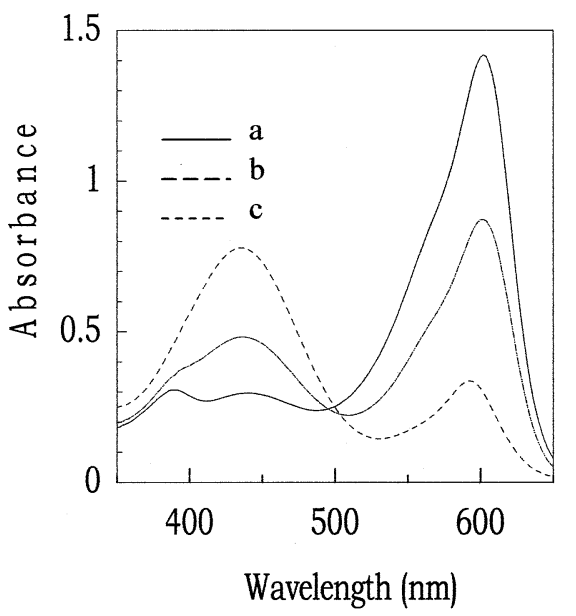

Fig. 17 Absorption spectra of BCPB solution. ${ }^{15}$ (a) HSA free; (b) $100 \mathrm{mg} / \mathrm{l} \mathrm{HSA}$; (c) $300 \mathrm{mg} / \mathrm{l} \mathrm{HSA}$; [BCPB], $3.5 \times 10^{-5} \mathrm{~mol} \mathrm{dm}^{-3}$; $\mathrm{pH}$, 3.0.

\section{Visual Colorimetry of Urinary Protein Using Membrane Filter}

A visual method was established for the determination of urinary protein. ${ }^{15-17}$ The method consists of ternary association between protein and Bromochlorophenol Blue (BCPB), extraction of the associate on a membrane filter (MF), and a significant color change of the dye by drying.

Since Taguchi et al. developed a membrane filtration method for solid-phase extraction, ${ }^{18,19}$ their method has been widely used for the determination of trace elements in water by many researchers. In this study, the high extractability of the ternary associate onto MF and the subsequent color change by drying provided a sensitive visual method for protein detection.

The absorption spectrum of the dye solution at $\mathrm{pH} 3.0$ primarily shows two spectral components with centers at 435 and $590 \mathrm{~nm}$ (Fig. 17). The acid dissociation constant was determined as $\mathrm{p} K_{\mathrm{a}}(\mathrm{OH})=4.2$ by spectrophotometry. Human serum albumin (HSA) was used for the investigation as a main urinary protein of medical importance. Increasing the HSA concentration diminishes the yellow band, while enhancing the blue component (Fig. 17). However, the sensitivity of the spectrophotometry is relatively poor.

Figure 18 shows an outline of the proposed method. The typical procedure is as follows: $3 \mathrm{~mL}$ of a sample solution was added to the dye solution adjusted to $\mathrm{pH} 3.0$ with a sodium chloroacetate buffer solution. The mixture was diluted to $5 \mathrm{~mL}$ with water. The solution was filtered with a membrane filter of mixed cellulose ester having $0.2 \mu \mathrm{m}$ pore size and $25 \mathrm{~mm}$ diameter (ADVANTEC). Then, the filter was dried in an oven

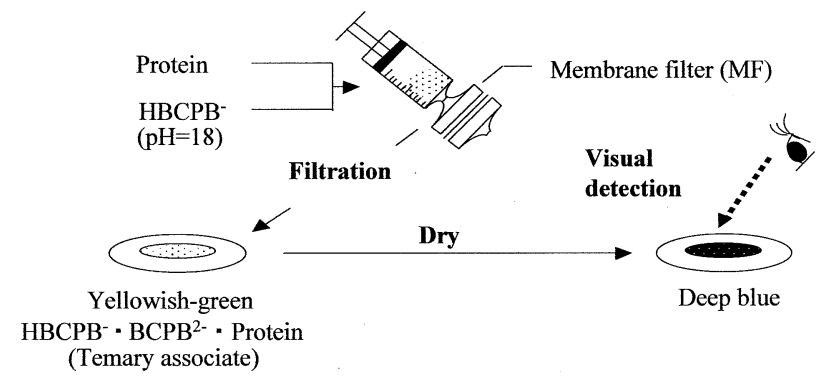

Fig. 18 Outline of the proposed method.
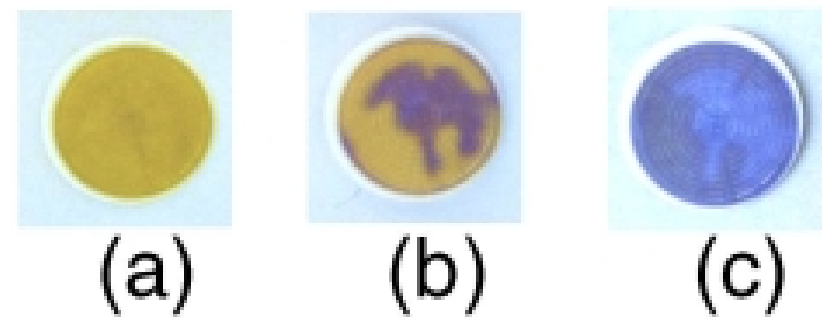

Fig. 19 Color change of MF by drying. ${ }^{16}$ [HSA], $5 \mathrm{mg} / \mathrm{l}$; [BCPB], $7.0 \times 10^{-5} \mathrm{~mol} \mathrm{dm}^{-3} ; \mathrm{pH}, 3.0$; sample volume, $5 \mathrm{ml}$; (a) wet; (b) during drying; (c) after drying.

at $60^{\circ} \mathrm{C}$ for $10 \mathrm{~min}$. The protein concentration was visually measured from the resulting color of the dried filter.

We found that a membrane filter displayed a greenish-yellow color immediately after filtration of a sample solution containing $\mathrm{BCPB}$ and HSA, while upon drying, the color changed from greenish-yellow to deep blue (Fig. 19). The blue color becomes darker with increased HSA content, and then the color becomes lighter after a critical HSA concentration (Fig. 20). The critical HSA concentration depends on the amount of the dye added. The deep blue region expands with increasing dye concentration. These results indicate that the ternary associate ( $\mathrm{HBCPB}^{-}-\mathrm{BCPB}^{2-}$-protein) with a high extractability forms in the presence of excess dye. Furthermore, the yellow dye, $\mathrm{HBCPB}^{-}$in the associate collected on a MF changes into the blue dye, $\mathrm{BCPB}^{2-}$, upon drying. In contrast, at HSA concentrations higher than the critical region, the binary associate ( $\mathrm{BCPB}^{2-}-$ protein) with a low extractability forms, resulting in a light blue color.

The visual detection limit is $40 \mathrm{mg} \mathrm{L}^{-1} \mathrm{HSA}$ in urine using a 10-hold dilution factor. There was good agreement between the results by the proposed method and those by the conventional Coomassie Brilliant Blue spectrophotometry. This method can be used as a screening test for low, but increasing levels of protein in urine.

The color change found in this study was extended to a solidphase extraction/visual colorimetry of Bence Jones protein, which is a bio-marker for the diagnosis of multiple myeloma. ${ }^{20}$

\section{Conclusion}

The methods reported here enable highly sensitive measurements of trace elements, even though these methods are composed of simple and easy operations. Some of our tests are commercially available, and others are currently being developed into commercial test kits. In general, it takes more 


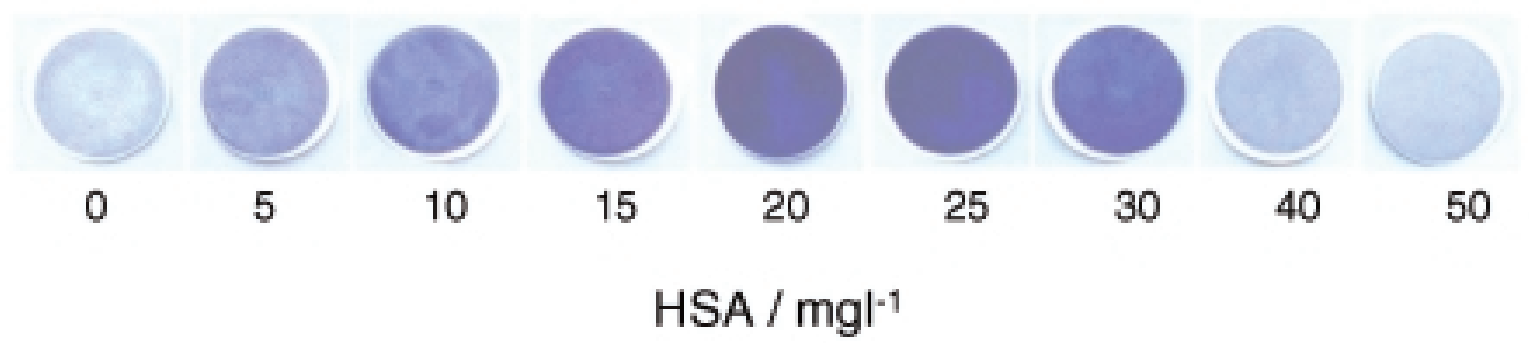

Fig. 20 Color transition with relation to protein concentration at low dye concentration. ${ }^{16}$ [BCPB], $7.0 \times 10^{-5} \mathrm{~mol} \mathrm{dm}^{-3} ; \mathrm{pH}, 3.0$; sample volume, $5 \mathrm{~cm}^{3}$.

than two years to modify a newly developed method into a test kit after the research is completed. In addition to test kits that can be implemented in field testing, there are other simple and inexpensive instruments being developed based on the results of our experiments. Those instruments will be practical in their simplicity and cost-effectiveness for the continuous monitoring of trace elements. We believe that the advantages of the visual tests reported here will be a great aid to the improvement of trace determination.

\section{Acknowledgements}

The author wishes to acknowledge Prof. Takao Yotsuyanagi, Ms. Hiroko Yasuda, Dr. Akihiko Ishida, Dr. Hitoshi Mizuguchi, Mr. Keitaro Yoshimoto, Mr. Junichi Isoe, and Mr. Keisuke Morita for their kind help with this article. The author also thanks Mr. Tomoyasu Hirota of the Geological Survey of Hokkaido for his useful advice and discussion about groundwater and aquifers.

\section{References}

1. E. Kaneko, H. Tanno, and T. Yotsuyanagi, Mikrochim. Acta, 1988, III, 333.

2. T. Tanaka, K. Hiiro, and A. Kawahara, Japan Analyst, 1974, 23, 650 .

3. E. Kaneko, H. Tannno, and T. Yotsuyanagi, Mikrochim. Acta, 1991, I, 37.

4. H. Mizuguchi, H. Yasuda, E. Kaneko, and T. Yotsuyanagi, Chem. Lett., 1997, 895.

5. H. Mizuguchi, E. Kaneko, and T. Yotsuyanagi, Analyst,
2000, 125, 1667.

6. T. Yotsuyanagi, E. Kaneko, H. Mizuguchi, and Y. Deguchi, Japan Patent Application, 1996, 12580.

7. T. Kurasawa, T. Yotsuyanagi, E. Kaneko, S. Saito, S. Hoshi, and K. Akatsuka, Bunseki Kagaku, 2002, 51, 833.

8. A. Ishida, E. Kaneko, and T. Yotsuyanagi, Chem. Lett., 1999, 217.

9. T. Yotsuyanagi, E. Kaneko, and A. Ishida, Japan Patent Application, 1994, 3393701.

10. A. Ishida, E. Kaneko, and T. Yotsuyanagi, Chem. Lett., 1999, 351.

11. T. Yotsuyanagi, E. Kaneko, and A. Ishida, Japan Patent Application, 1998, 326309.

12. E. Kaneko, J. Isoe, T. Iwabuchi, S. Hoshi, K. Akatsuka, and T. Yotsuyanagi, Analyst, 2002, 127, 219.

13. T. Yotsuyanagi, E. Kaneko, and Y. Sakai, Japan Patent Application, 2000, 221180.

14. J. Isoe, Y. Sakai, E. Kaneko, S. Saito, S. Hoshi, and K. Akatsuka, Bunseki Kagaku, 2002, 51, 1037.

15. K. Yoshimoto, E. Kaneko, and T. Yotsuyanagi, Chem. Lett., 2000, 6.

16. K. Yoshimoto, E. Kaneko, and T. Yotsuyanagi, Bunseki Kagaku, 2000, 6, 363.

17. T. Yotsuyanagi, E. Kaneko, and K. Yoshimoto, Japan Patent Application, 1998, 304803.

18. S. Taguchi, H. Itooka, and K. Goto, Bunseki Kagaku, 1984, 453.

19. S. Taguchi and K. Goto, Bunseki Kagaku, 1989, 524.

20. E. Kaneko, S. Hoshi, K. Akatsuka, T. Kurasawa, T. Yotsuyanagi, and $\mathrm{H}$. Yoshimura, Proceedings of International Congress on Analytical Sciences 2001, 2001, 196. 